\title{
The use of bicycle desks to increase physical activity in two special education classrooms
}

\section{BACKGROUND}

Although the literature has predominantly focused on elementary youth, preliminary findings indicate that attentional benefits may arise from adolescent physical activity as well. Limited research has examined the impact of classroom-based physical activity for secondary students, and no research to date has explored bicycle workstations as a means to improve physical activity within the special education classroom.

\section{PARTICIPANTS AND PROCEDURE}

Two special education resource classrooms within a high school took part in the research study. Students were given the option of riding on the bike or sitting on chairs in each classroom. Heart rate, calories, miles, time, and on-task behavior data were collected. In addition, student acceptability of bikes was explored.

\section{RESULTS}

The results indicated that the overall mean heart rate during bike riding was significantly higher than the overall mean heart rate when seated on a traditional chair. Also a significant main effect was found for time on calories expended while riding. No significant results were found for miles or on-task behavior.

\section{CONCLUSIONS}

Overall, students enjoyed the use of bicycles during class, found the bicycle workstations to be beneficial to their learning, and appeared to note as many benefits as limitations with the bicycle workstations. Limitations and future directions are discussed.

\section{KEY WORDS}

exercise; school; workstation; FitDesk

ORGANISATION - 1: University of Kentucky, USA · 2: University of Miami, USA

Authors' CONtributions - A: Study design - B: Data collection · C: Statistical analysis · D: Data interpretation ·

E: Manuscript preparation · F: Literature search · G: Funds collection

CORRESPONDING AUTHOR - Colleen Cornelius, University of Kentucky, 170-H Taylor Education Building, 40506 Lexington, USA, e-mail: colleen.cornelius@uky.edu 


\section{BACKGROUND}

Children weigh more and have a higher body mass index (BMI) than they did a decade ago (Ogden, Carroll, Kit, \& Flegal, 2014). In fact, more than one-third of today's youth and adolescents are overweight or obese (Ogden et al., 2014) and less than $30 \%$ of children (ages 6-17 years old) currently meet the daily recommendations of 60 minutes of accumulated physical activity (Centers for Disease Control and Prevention [CDC], 2015; World Health Organization [WHO], 2016). Participation in exercise declines as children age (CDC, 2015), with only one-quarter of high school students reporting that they meet daily physical activity requirements (CDC, 2015). The 2008 Physical Activity Guide for Americans (U.S. Department of Health and Human Services, 2008) outlines specific activities for children, adults, older adults, pregnant women, and adults with disabilities; however, no guidelines are included for children with disabilities. Although approximately $18 \%$ of children and adolescents in the United States have a chronic condition or disability (Murphy \& Carbone, 2008), the research that has been conducted on children identified with disabilities suggests that when compared to their typically developing peers, the frequency of physical activity is significantly lower for children with intellectual disabilities (King, Shields, Imms, Black, \& Ardern, 2013), physical impairments (Rimmer \& Rowland, 2008; Sit, McManus, McKenzie, \& Lian, 2007), cerebral palsy (Zwier et al., 2010), autism spectrum disorders (Borremans, Rintala, \& McCubbin, 2010; Sowa \& Meulenbroek, 2012), and visual impairments (Perkins, Columna, Lieberman, \& Bailey, 2013; Schedlin, Lieberman, Houston-Wilson, \& Cruz, 2012). In addition, children with disabilities are significantly less active in organized physical activities, spend more time in extracurricular activities that are sedentary in nature (Law et al., 2006), and have obesity rates that are $38 \%$ higher than children without disabilities (Bandini, Curtin, Hamad, Tybor, \& Must, 2005).

These findings occur despite established knowledge of the benefits of physical activity for children (CDC, 2015; WHO, 2016). Further, physical activity may extend to other areas of healthy living, specifically academic achievement as a result of on-task behavior for both typically developing children and those with special needs (Donnelly et al., 2016; Fedewa \& Ahn, 2011; Luke, Vail, \& Ayres, 2014). Although the literature has predominantly focused on elementary youth (e.g., Mahar et al., 2006; Mura, Vellante, Nardi, Machado, \& Carta, 2015), preliminary findings indicate that attentional benefits may arise from adolescent physical activity as well (e.g., Chang, Labban, Gapin, \& Etnier, 2012; Staiano, Abraham, \& Calvert, 2012). As attention and on- task behavior enhance academic learning (Donnelly et al., 2016; Kohl \& Cook, 2013), a present gap in the literature exists.

\section{THE EFFECT OF PHYSICAL ACTIVITY ON BEHAVIOR}

The Centers for Disease Control and Prevention (CDC, 2015) has publicly recognized that physical activity may support academic behavior (i.e., timeon-task) and classroom focus, and these gains occur independently of weight status (Davis, Tkacz, Tomporowski, \& Bustamante, 2015). One session of physical activity can improve attention (Hillman et al., 2009; Janssen, Toussaint, van Mechelen, \& Verhagen, 2014b; Pontifex, Scudder, Drollette, \& Hillman, 2012), increase working memory (Benzing, Heinks, Eggenberger, \& Schmidt, 2016; Pontifex, Hillman, Fernhall, Thompson, \& Valentini, 2009), enhance academic learning time (Bartholomew \& Jowers, 2011; Webster, Wadsworth, \& Robinson, 2015), and improve the development of anterior frontal brain patterns that support task completion and lesson comprehension (Chaddock-Heyman et al., 2013).

\section{THE EFFECT OF PHYSICAL ACTIVITY ON CHILDREN WITH DISABILITIES}

Data from a Canadian national study revealed that children and adolescents with disabilities $(N=319)$ were 4.50 times more likely to be inactive when compared to their non-disabled peers $(N=7020)$ (Rimmer \& Rowland, 2008). This indicates that children with disabilities are lacking the opportunities to engage in healthpromoting physical activity. Although this segment of the population may engage in less physical activity than the general student body, research has shown that regular moderate-to-vigorous physical activity can lead to significant improvements in the cognitive and physical health of children with disabilities. A study by Bowling et al. (2017) showed that children with behavioral health disorders $(N=103)$ participating in a Cybercycle intervention had $32 \%$ to $51 \%$ lower odds of poor self-regulation and discipline-associated issues while participating in the intervention. This improvement in behavior has the potential to increase the amount of time that children can participate in classroom lessons and be involved in classroom activities. Improvements in aerobic ability, gross motor function, and exercise satisfaction were found in three systematic reviews and 14 studies pertaining to children with developmental disabilities (Johnson, 2009). Such results support the idea that disabled children can make progress physically, with the incorporation of regular physical activity. It also shows that these children 
may have enhanced attitudes towards physical activity if given appropriate opportunities to remain active.

\section{OPPORTUNITIES FOR PHYSICAL ACTIVITY IN SCHOOL}

Schools offer a logical and feasible setting to increase daily physical activity for youth (Kohl \& Cook, 2013; National Center for Education Statistics, 2016). Although, in the past, finances and state-wide testing have been barriers to incorporating physical activity into the school day (Hernandez, 2014; Lounsbery, McKenzie, Trost, \& Smith, 2011), to date, research has not reflected a negative impact of physical activity on academic achievement (CDC, 2010; Donnelly et al., 2016; Mura et al., 2015). Of recent interest, physical activity has been used within the classroom as part of the academic lesson (Carlson et al., 2015; Have et al., 2016; Kibbe et al., 2011; Mulrine, Prater, \& Jenkins, 2008) or as breaks from instruction (e.g., Bailey \& DiPerna, 2015; Caldwell \& Ratliffe, 2014; Janssen et al., 2014a). When classroom-based physical activity is incorporated into the classroom setting, post-activity outcomes include better attention (Grieco, Jowers, \& Bartholomew, 2009; Bartholomew \& Jowers, 2011; Kibbe et al., 2011), improved on-task behaviors (Carlson et al., 2015; Mahar et al., 2006), and increased academic performance (Donnelly \& Lambourne, 2011; Have et al., 2016). Mahar and colleagues (2006) found that third $3^{\text {rd }}$ and $4^{\text {th }}$ graders who participated in Energizers participated in more physical activity during the day and increased their on-task engagement by over $20 \%$ when compared to baseline measures. Janssen and colleagues (2014a) found improvements in selective attention among 10-11-year-old children ( $n=123)$ after a 15-minute experimental break (i.e., no break - continuing a cognitive task, passive break - listening to a story; moderate-intensity break jogging, passing, dribbling; and vigorous-intensity break - running, jumping, skipping), with the largest effect being found for a moderate-intensity break.

Currently, however, school-based physical activity studies are dominated by elementary school samples (e.g., Carlson et al., 2015; Have et al., 2016; Mulrine et al., 2008; Whitt-Glover, Ham, \& Yancey, 2011), which may be due to heightened academic demands of testing for adolescents (Kohl \& Cook, 2013). Older students, however, benefit from physical activity within the school day as well (Verburgh, Königs, Scherder, \& Oosterlaan, 2013). Chang et al. (2012) in a meta-analysis of 79 studies reported that larger effects were found for high school versus elementary youth samples engaging in acute exercise. Further, Owen and colleagues (2016) found that physical activity during the school day was associated with increased school engagement for both children and adolescents, but more so for adolescents. As such, physical activity within the school day is beneficial for all ages.

\section{AIM OF THE STUDY}

Limited research has examined the impact of classroom-based physical activity for secondary students (Fedewa, Abel, \& Erwin, 2017a), and no research to date has explored classroom-based physical activity within the special education classroom for students with disabilities. As research points to a rising trend in the number of adolescents not participating in physical activity and supports the benefits of physical activity for both adolescents and children receiving special education, a gap in the research currently exists. FitDesks (http://www.thefitdesk.com), or bicycle workstations, may be a plausible intervention to increase physical activity for adolescents. Previous research (Fedewa et al., 2017a; Joubert, Kilgas, Holley, \& Drum, 2015; Pilcher \& Baker, 2016) has shown preliminary effectiveness for enhancing physical activity through the use of these bicycle workstations. Fedewa and colleagues (2017a) used FitDesks in an alternative school setting, while Joubert et al. (2015) and Pilcher and Baker (2016) used them with college students and adults; all three studies found significantly increased physical activity levels. The present study, therefore, sought to examine the impact of physical activity in two secondary resource classrooms on physical activity and behavioral outcomes. Based on prior literature, it was hypothesized that students will engage in more physical activity when riding the bicycle workstations and that students' on-task engagement will increase when using the FitDesks as well. Last, based on one prior study showing relatively high student acceptance and enjoyment of the FitDesks (Fedewa et al., 2017a), student acceptance and enjoyment of the bicycle workstations was explored as well.

\section{PARTICIPANTS AND PROCEDURE}

\section{PARTICIPANTS}

The setting of the study was an urban secondary school in the Southeast United States. Two special education resource classrooms within the high school took part in the research study. The resource classrooms served a total of 11 different groups of students (6 groups in one classroom and 5 groups in the other) during the school day $(N=88)$. See Table 1 for the disability status of youth participants. After full approval from the University Institutional Review Board, parental consent forms were sent home
Physical activity in special education classrooms 
Table 1

Participant grade and disability status

\begin{tabular}{lcccc}
\hline Disability & \multicolumn{3}{c}{ Number in each grade } \\
\cline { 2 - 4 } & 9 & 10 & 11 & 12 \\
\hline Specific learning disorder & 12 & 7 & 10 & 0 \\
Autism spectrum disorder & 4 & 2 & 1 & 1 \\
Mild mental disability & 5 & 3 & 2 & 0 \\
Functional mental disability & 0 & 2 & 0 & 6 \\
Emotional behavioral disorder & 1 & 10 & 0 & 4 \\
Other health impairment & 15 & 0 & 1 & 0 \\
Hearing impairment & 0 & & & \\
\hline Note. ${ }^{*}$ All students had an ADHD diagnosis. & & 2 &
\end{tabular}

Alicia Fedewa, Colleen Cornelius, Elizabeth Whitney, Soyeon Ahn, Mary Comis

Note. *All students had an ADHD diagnosis.

to the students' parents. One group of students did not have any consent forms returned. Out of the 88 students, parental consent and student assent were obtained from 41 students ( $47 \%$ consent participation rate) across 11 groups of students. Of the 41 students with consent, 8 were female $(20 \%)$ with the average student age of 14.97 years $(R=14-18)$. Within each group of students, there were approximately 4 students who had parental consent to ride the bicycle workstations during the day.

\section{PROCEDURE}

Six bicycle workstations (FitDesks) were situated in each classroom along with their regular desks for 16 weeks. Class periods were 60 minutes long, and students were free to choose whether to use the bikes or remain seated at their regular desks. Given that there were six bicycle workstations in each classroom but typically only four students who had parental consent, students who did not have parental consent were free to ride the bicycle workstations only if those students with consent chose not to ride the bike (no physical activity data were collected on students without consent, although on-task behavioral data were collected as these data were aggregated and did not identify the student, as per University Institutional Review Board guidelines). Students were instructed on how to put on their heart rate monitors and record their data on the hard copy logs described in further detail below.

In addition to baseline data collection, data were collected in three additional waves. Data collection waves spanned two weeks (10 school days). Students were given the option of riding on the bikes or sitting on chairs. Students wore the heart rate monitors on the bikes and while seated on the traditional chairs. The average heart rate and total calories of each stu- dent were collected for the duration of each class period and recorded in an activity log that each student kept for the duration of the study. These activity logs recorded the time spent seated on the chair or on the bike as well as the respective physical activity data. Students on bicycle workstations recorded their heart rates and total calories as well as additional data provided from the bicycle workstations (miles, resistance level, time) while on the bicycle workstations. Students in traditional chairs recorded their heart rates in the activity log. These data were totaled and averaged based on the total minutes seated on the chair or at the bicycle workstation. At the end of the intervention period (16 weeks), students were given a survey evaluating their acceptance and enjoyment of the bicycle workstations (described below).

\section{INSTRUMENTS}

Physical activity. Students were prompted to wear heart rate monitors (Polar F4) around their chests during the data collection periods. Five student researchers trained by the lead researchers in attaching and monitoring the fidelity of the heart rate monitor were present during each day of the data collection periods (40 school days in total). The student researchers ensured that students were wearing their heart rate monitors and were logging the data from their FitDesk screens. The data from the screens included miles, resistance, and time.

Student behavior. Observers assessed on/off task behavior of up to six students in each class period (5 minutes per student) for a total of 60 minutes each day. Neither the teacher nor the student knew which students were being observed at any given time; the observers randomly chose the order of the students. Momentary time sampling observations were recorded, similar to previous research (Mahar et al., 
2006; Webster et al., 2015). Observations occurred at 10 -second intervals signaled via a timing app (Simple Interval Time [SIT] for Apple phones and IntervalTimer for Android users) that the observers listened to with headphones. After each 10-second interval, the observers had 5 seconds to record on a document whether the student was on-task (verbal and motor behavior that follows class rules and is appropriate to the learning situation), motor off-task (fidgeting, drawing, restless), noise off-task (talking to a peer or speaking out) or passive/other off-task (gazing off, no eye contact, head down). After 1 minute (four observations), the observers rotated to another student. Rotations from student to student occurred five times in random order until each student had been observed for a total of 5 minutes (20 observations for each student). Students were observed for 6 weeks, five times each week, for a total of 30 days. The occurrence of behaviors was totaled and divided by the interval time, resulting in a percentage of on-task/ off-task behavior while riding bicycle workstations compared to on-task behavior in a traditional chair.

Student perception of bike workstations. At the end of the intervention, students were given an 11-item survey that has been validated in prior studies (Fedewa et al., 2017a; Fedewa, Cornelius, \& Ahn, 2017b). The scale consists of three factors: perceived academic benefits of riding bicycle workstations in class $(\alpha=.89)$, enjoyment of riding the bicycle workstations in class $(\alpha=.86)$ and limitations of riding the bicycle workstations in class $(\alpha=.64)$. Example items include: "Riding a bicycle in class helped me listen better to the teacher", and "I preferred sitting on the bike than on the chair during class".

\section{DATA ANALYSIS}

The first research question related to students' heart rate was answered using a linear mixed-effects (growth curve) model, in which students' heart rate was modeled as an outcome using three predictors: time, whether the student was riding the bicycle workstation or not, and their interaction. Parameters estimated in a linear mixed-effects model included (1) the main effect of time, which examined whether the overall heart rate significantly changed over time, (2) the main effect of whether the student was riding the bicycle workstation or not, comparing average heart rate over time between bike riding and sitting traditionally, and (3) their interaction, which examined whether the difference in heart rates between bike riding and traditional chair sitting varied depending on time. In a linear mixed-effects model, all three terms were initially treated as random and then fixed when found not to randomly vary. In all models, both random and fixed parameters were estimated using the maximum likelihood estimation (MLE) method, which accounts for missing data. Then, the effects of bike riding on the calories expended while bike riding and distance accumulated on the bike in miles were examined using a linear mixed-effects model, in which each outcome - student's calories expended and distance ridden by bike - was modeled as an outcome using time as a predictor. The parameter estimated in each linear mixed-effects model was the main effect of time, which examined whether the overall calories and distance significantly changed over time. In a linear mixed-effects model, the effect of time was initially treated as random and then fixed when found not to vary randomly. In all models, both random and fixed parameters were estimated using the MLE method, which accounts for missing data.

The second research question was addressed by comparing the average percentage of on-task behavior when riding bicycle workstations to the average percentage of on-task behavior when seated on a traditional chair using $z$-statistics, which is computed by dividing the difference in proportions by the standard error of the difference in proportions. The last research question was addressed by examining bivariate correlations between physical activity level (i.e., average heart rate, average calories expended while riding the bike, and distance accumulated in miles on the bike) and the student perception of riding on the bicycle workstations (i.e., overall perception, academic benefits, enjoyment of riding the bike, and limitations of riding the bike). All statistical analyses were performed using SPSS.

\section{RESULTS}

\section{EFFECTS OF BICYCLE WORKSTATIONS ON HEART RATE, CALORIES, AND DISTANCE}

Descriptive statistics (see Table 2) revealed that students rode the bicycle workstations for approximately a third of the class time $(M=21$ minutes, $S D=5.26)$ compared to the amount of time that they chose to sit on their traditional chairs $(M=32$ minutes, $S D=4.32)$ and that the amount of time spent on the bikes or on the chairs was not significantly different over time $(F(2,151)=2.68, p=.069)$.

Results from a linear mixed-effects model suggest that the main effect of bike riding was found to be statistically significant $(F(1,241.54)=17.41, p<.001)$, showing that the overall mean heart rate during bike riding was significantly higher than the overall mean heart rate when seated on a traditional chair $(t(241.54)=4.17, p<.001)$. Specifically, the mean difference in overall average heart rate was 15.84 with a standard error of 3.02 (95\% CI: 9.94-21.73), suggesting that riding on bicycle workstations contributed to a significant increase in heart rate $(M=103.45$,
Physical activity in special education classrooms 
Table 2

Descriptive statistics for variables

\begin{tabular}{|c|c|c|c|c|c|c|}
\hline Wave & Variable & $n$ & $\min$ & $\max$ & $M$ & $S D$ \\
\hline \multirow[t]{3}{*}{1} & miles & 77 & 1.00 & 24.00 & 5.59 & 3.94 \\
\hline & calories & 81 & 9.20 & 378.90 & 120.49 & 67.01 \\
\hline & heart rate & 77 & 82.00 & 145.00 & 107.32 & 13.29 \\
\hline \multirow[t]{3}{*}{2} & miles & 57 & 0.26 & 49.08 & 4.64 & 6.80 \\
\hline & calories & 56 & 6.48 & 272.30 & 83.28 & 48.01 \\
\hline & heart rate & 58 & 75.00 & 120.00 & 97.19 & 11.82 \\
\hline \multirow[t]{3}{*}{3} & miles & 10 & 0.00 & 3.90 & 1.83 & 1.28 \\
\hline & calories & 11 & 0.00 & 94.10 & 55.07 & 30.42 \\
\hline & heart rate & 11 & 83.00 & 114.00 & 100.18 & 9.85 \\
\hline \multirow[t]{3}{*}{4} & miles & 10 & 0.47 & 9.36 & 3.95 & 3.19 \\
\hline & calories & 10 & 11.40 & 116.20 & 56.22 & 40.48 \\
\hline & heart rate & 8 & 78.00 & 109.00 & 95.00 & 10.88 \\
\hline Wave & On-task behaviors & & & & & \\
\hline \multirow[t]{2}{*}{1} & sitting & 9 & 0.49 & 0.94 & 0.73 & 0.16 \\
\hline & bike & 9 & 0.43 & 1.00 & 0.77 & 0.17 \\
\hline \multirow[t]{2}{*}{2} & sitting & 9 & 0.6 & 0.85 & 0.70 & 0.08 \\
\hline & bike & 9 & 0 & 0.95 & 0.52 & 0.42 \\
\hline \multirow[t]{2}{*}{3} & sitting & 9 & 0 & 0.96 & 0.72 & 0.31 \\
\hline & bike & 9 & 0 & 1.00 & 0.43 & 0.49 \\
\hline
\end{tabular}

$S E=6.64)$ when compared to the heart rate when seated on a traditional chair $(M=87.23, S E=6.94)$. Neither the main effect of time $(F(1,4394.53)=0.24$, $p=.722)$ nor the interaction effect of time and traditional chair sitting $(F(1,186.62)=2.81, p=.058)$ was found to be statistically significant.

Results from a linear mixed-effects model suggest a significant main effect of time $(F(1,148)=4.82$, $p=.026)$ on calories expended while bike riding. In particular, a statistically significant decrease over time in calories expended while bike riding was found $(b=-5.66, S E=2.58, t(148)=-2.19, p=.037)$, suggesting that on average calories expended would be decreased by 5.66 calories over time. However, no main effect of time was found on miles ridden on the bike $(F(1,144)=0.27, p=.669)$, suggesting no significant change in miles accumulated on the bike over time.

\section{EFFECTS OF PHYSICAL ACTIVITY ON ON-TASK BEHAVIOR}

The average proportion of on-task behaviors for bicycle workstations aggregated over time $(p=.573)$ was not significantly different from the average propor- tion of on-task behaviors when students were seated on chairs $(p=.717), z=-1.11, p=.266$. This result suggests that students show the same rate of on-task behaviors when using the bicycle workstations compared to when students are seated on chairs.

\section{STUDENT PERCEPTIONS OF USING BICYCLE WORKSTATIONS}

Table 3 shows the descriptive statistics for the overall student perceptions of riding the bicycle workstations and the three subscales of the survey: academic benefits of the bike, enjoyment of the bike, and limitations of the bike. Overall, students enjoyed the use of bicycles during class $(M=3.77)$, found the bicycle workstations to be beneficial to their learning $(M=3.63)$ and appeared to note as many benefits as limitations with the bicycle workstations $(M=3.00)$. Student perceptions of using the bicycle workstations and the three subscale scores were not significantly correlated with the average calorie expended while bike-riding $(r=.11, p=.566$ for total scores on student perceptions of bicycle workstations; $r=-.03$, $p=.905$ for academic benefits; $r=-.23, p=.268$ for 


\begin{tabular}{lllll}
\hline & $\min$ & $\max$ & $M$ & $S D$ \\
\hline Overall perception of bicycle stations & 2.64 & 4.82 & 3.77 & 0.58 \\
Academic benefits & 1.00 & 5.00 & 3.63 & 1.35 \\
Enjoyment of bicycle stations & 1.25 & 5.00 & 4.31 & 1.40 \\
Limitations of bicycle stations & 1.00 & 5.00 & 3.00 & 1.30 \\
\hline
\end{tabular}

Note. $n=26$; Likert scale of 1 (definitely false) to 5 (definitely true).

enjoyment of the bike; $r=.24, p=.242$ for limitations of the bike), average heart rate $(r=-.17, p=.388$ for total scores on student perceptions of bicycle workstations; $r=-.01, p=.978$ for academic benefits; $r=-.13, p=.521$ for enjoyment of the bike; $r=.002$, $p=.994$ for limitations of the bike), and total miles accumulated on the bike $(r=.24, p=.238, S D=.58$ for total scores on student perceptions of bicycle workstations; $r=.06, p=.776, S D=1.35$ for academic benefits; $r=-.13, p=.544, S D=1.40$ for enjoyment of the bike; $r=.36, p=.068, S D=1.30$ for limitations of the bike). However, significant relationships were found between academic-related on-task behavior and enjoyment of riding the bicycle workstation $(r=.53$, $p=.005)$, indicating that students who enjoy riding the bicycle workstation in class also report that the bikes help with their academic-related on-task behavior.

\section{DISCUSSION}

The present study examined the impact of physical activity in two secondary resource classrooms on physical activity and behavioral outcomes. For our primary research question, we hypothesized that students would have more physical activity time when riding the bicycle workstations. The results supported our hypothesis in that students who were given the opportunity to use the FitDesks had significantly higher heart rates and calories expended than students who were seated on the chairs. This is particularly important as students were not required to use the bicycle workstations for the project, but instead were given the choice. Those who had parental consent ended up choosing to ride the bicycle workstations each time they came to class, even when the researchers were not present to collect data, indicating that students enjoyed the bicycle workstations and used them during instructional time. Data indicated that about a third of the time was spent riding the bike during class and that the amount of time riding the bicycle workstation was fairly consistent over the duration of the study. However, the results did indicate that the calories expended decreased over time, showing that students exerted less energy on the bicycle workstations as the study progressed. This finding could be explained in several ways. It is possible that students grew more fatigued with using the bikes as the study progressed as they had lost the novelty effect of using the workstations in the classroom (Caldwell \& Ratliffe, 2014). It is possible that if a student's health and academic work improve while using the workstations, then the student may continue to exert higher levels of physical activity on the bicycles. However, if a student who is not intrinsically motivated and has no extrinsic motivation (positive teacher feedback, reflection of higher grades) either, that student may not continue to consistently exert the same levels of energy on the bicycle. Prior research has supported that both intrinsic and extrinsic motivators contribute to physical activity participation for students who are relatively new at exercising (Buckworth, Lee, Regan, Schneider, \& DiClemente, 2007). Further, students may expend fewer calories if no extrinsic motives, such as goals, are offered. The importance of goal setting and extrinsic motivators in physical activity participation and sustainability was shown in a prior study wherein students who had a target of physical activity accumulation and who received an extrinsic reward when that goal was reached accumulated significantly more physical activity than students without the goal or reward (Hardman, Horne, \& Lowe, 2011). Goal setting is one way to shape self-efficacy for exercise (Zimmerman, Bandura, \& Martinez-Pons, 1992), which has been shown in previous literature to increase physical activity (e.g., D’Haese et al., 2016; Ray \& Henry, 2011; Ross, Dowda, Beets, \& Pate, 2013). Perhaps setting goals would have motivated some students to increase their self-efficacy for physical activity, causing them to exert more effort as the study progressed.

Another possible explanation could be the required instructional task, a variable not assessed in the current study. In a previous study that compared cognitive engagement versus physical engagement, student heart rates were higher when they were physically active during a cognitive task (such as what student participants in the present study were often asked to do with in-class assignments) compared to students who were completing a cognitive task with no physical exertion (Schmidt, Benzing,
Physical activity in special education classrooms 
Alicia Fedewa, Colleen Cornelius, Elizabeth Whitney, Soyeon Ahn, Mary Comis
\& Kamer, 2016). It is possible that there were more instructional demands on students at the beginning of the intervention and that the difficulty of these cognitive tasks may have decreased over time. It would be informative to tease out these variables to determine what effect the type of assignment or on-task requirement has on physical activity exertion when using bicycle workstations.

Our second hypothesis examined whether students would have higher levels of on-task behavior when riding the bicycle workstations then when seated on traditional chairs. Our results did not support this hypothesis, as students had the same level of on-task behavior on and off the bicycle workstations. In previous research that has looked at the difference between the use of FitDesks and sedentary behavior while completing cognitive tasks in college students, it was also found that there was no difference in on-task engagement between bicycle workstations and traditional chairs (Pilcher \& Baker, 2016). A possible explanation for the present study's findings is that taking breaks from using the bicycle workstations could also impact student attention or on-task behavior. A study by Janssen and colleagues (2014a) found that taking any kind of break from a cognitive task resulted in students who were more on-task. The present study did not assess how many times students took physical activity breaks (i.e., stopped pedaling) or took a break from their required task. Ariga and Lleras (2011) suggested that maintaining cognitive control over a prolonged period of time can be improved by switching tasks, while Ralph, Onderwater, Thomson, and Smilek (2017) found significance for both switching tasks and simply taking breaks. In either case, taking breaks from a prolonged task, such as an academic assignment or riding the bike for an extended period of time, may disrupt the monotony of the activity and promote increased engagement (Ralph et al., 2017), causing an increase in ontask behavior as well. Future studies could elucidate whether taking a break while using the FitDesk could impact the results of student on-task behaviors.

Last, we explored whether students in resource classrooms would indicate the same level of acceptability and enjoyment of the bicycle workstations as a prior sample of high school students (Fedewa et al., 2017a). Similar to the prior study, students in the present study perceived the bicycle workstations to be helpful to their learning and found riding the bicycles during class enjoyable. A prior study researched teacher and student perceptions of active classroom activities, finding that students enjoyed the integration of an active classroom program because they were "fun", "exciting”, and "enjoyable" (Martin \& Murtagh, 2015). This supports our findings that physical activity in the classroom is enjoyable, which may be beneficial to student learning, if perhaps through the mechanism of school and task enjoyment.

\section{LIMITATIONS}

Although the findings indicated benefits for student physical activity and enjoyment of the bicycle workstations, there were several limitations to note in the present study. For one, a small sample size was used due to the inherent nature of exploring outcomes for children receiving special education services. On average, there were eight students per class, and only $47 \%$ of those had consent to participate in the study. A larger sample size would have enhanced the power in our analyses to draw more definitive conclusions about the use of bicycle workstations in special education classrooms. In addition, one major limitation to conducting research in schools and allowing students and teachers to use the bicycle workstations as they chose is that the research protocol was teacher-dependent. Occasionally the classroom teacher trained in the research protocol was absent and a substitute, who was not trained, taught classes. In addition, the classroom environment (i.e., explicit classroom rules) differed across teachers, such that in some classrooms students were permitted to talk to each other while working and in others complete silence was the expectation during work time. A final limitation is that randomization was not used for this design due to the logistical constraints of working with a small sample in a special education classroom setting. A true control group was not established, as a within-subjects design was used for this study. Examining the impact of bicycle workstations in special education classrooms using a randomized design with a wait-list control would allow us to more accurately establish behavioral effects from using bicycle workstations that could be generalized to other special education classrooms.

\section{CONCLUSION AND FUTURE DIRECTIONS}

FitDesks are beneficial to improving physical activity levels of students within secondary resource classrooms. Students who used the bicycle workstations during class had higher heart rates and calories expended than students who sat on traditional chairs. Although the value of calories expended by students who took advantage of the bicycle workstations was higher than those who did not, the calories over time decreased. These findings suggest that although the amount of calories over time does not increase (likely due to lower levels of exertion), FitDesks continue to improve students' accumulation of light-intensity physical activity during the school day. Future research should examine the reasons why these calories may decrease over time, specifically investigating how the instructional and task demands may change 
over time in resource classrooms. Further, future studies could also investigate how various levels of physical activity intensity on the bikes (from light to vigorous) may affect students' ability to remain on-task and retain academic material. Elliot et al. (2015) examined the effects of various physical activity levels and how they were associated with school burnout in a secondary vocational school. The study found that those who reported and characterized their physical activity as vigorous also selfreported lower levels of school burnout. Perhaps if students find the FitDesk bicycles enjoyable and are also coached to engage in more high-intensity pedaling while in the classroom, student on-task behavior and academic outcomes may improve.

The present study also showed that bicycle workstations are associated with student's reported academic on-task behavior, but not on-task behavior as observed by researchers. Yet students still reported that they enjoyed the FitDesks and found them to be beneficial to their learning. Further research should examine the effects of FitDesks for students displaying different cognitive and physical needs within the classroom. This study found that the on-task behavior was the same for those on the traditional chairs and those at the bicycle workstations. To better explore this outcome, it would be beneficial for future research to investigate how it varies within specific disabilities, especially those disorders that include attention deficits, such as ADHD. Given that the present study combined specific language disorders, autism, mild mental disabilities, functional mental disabilities, emotional behavioral disorders, hearing impairments, and other health impairments in the analysis, future research could tease these disabilities apart to explore possible differential effects across disabilities or presenting concerns.

Future research should also compare the self-efficacy levels between those who ride the bicycle workstations during class and those who sit on normal chairs. Data may suggest that since there was no differential correlation between the bicycle workstation and traditional chairs when looking at on-task behavior, there is a possibility that the bikes improved self-efficacy levels as students who enjoyed riding the bikes believed that it improved their academic on-task behavior. Prior studies have demonstrated that when adolescents meet their recommended activity level they also report higher levels of selfefficacy (Rutkowski \& Connelly, 2012). Another study found that the use of a FitDesk while in the classroom improves students' affect and motivation (Pilcher \& Baker, 2016), which can be closely related to self-efficacy. Therefore, to further understand this outcome, future research should look at those differences in student self-efficacy, specifically in their academic work.

\section{REFERENCES}

Ariga, A., \& Lleras, A. (2011). Brief and rare mental "breaks" keep you focused: Deactivation and reactivation of task goals preempt vigilance decrements. Cognition, 118, 439-443. https://doi.org/10.1016/j. cognition.2010.12.007

Bailey, C. G., \& DiPerna, J. C. (2015). Effects of classroom-based Energizers on primary grade students' physical activity levels. Physical Educator, 72, 480-495.

Bandini, L. G., Curtin, C., Hamad, C., Tybor, D. J., \& Must, A. (2005). Prevalence of overweight in children with developmental disorders in the continuous national health and nutrition examination survey (NHANES) 1999-2002. Journal of Pediatrics, 146, 738-743. https://doi.org/10.1016/j. jpeds.2005.01.049

Bartholomew, J. B., \& Jowers, E. M. (2011). Physically active academic lessons in elementary children. Preventive Medicine, 52, 51-54. https://doi. org/10.1016/j.ypmed.2011.01.017

Benzing, V., Heinks, T., Eggenberger, N., \& Schmidt, M. (2016). Acute cognitively engaging exergamebased physical activity enhances executive functions in adolescents. PLoS One, 11, e0167501. https://doi.org/10.1371/journal.pone.0167501

Borremans, E., Rintala, P., \& McCubbin, J. A. (2010). Physical fitness and physical activity in adolescents with Asperger syndrome: A comparative study. Adapted Physical Activity Quarterly, 27, 308-320. https://doi.org/10.1123/apaq.27.4.308

Bowling, A., Slavet, J., Miller, D., Haneuse, S., Beardslee, W., \& Davison, K. (2017). Cybercycling effects on classroom behavior in children with behavioral health disorders: An RCT. Pediactrics, 139. https:// doi.org/10.1542/peds.2016-1985

Buckworth, J., Lee, R. E., Regan, G., Schneider, L. K., \& Diclemente, C. C. (2007). Decomposing intrinsic and extrinsic motivation for exercise: Application to stages of motivational readiness. Psychology of Sport and Exercise, 8, 441-461. https://doi. org/10.1016/j.psychsport.2006.06.007

Caldwell, T., \& Ratliffe, T. (2014). Investigation of intensity levels during video classroom exercise sessions. Physical Educator, 71, 473-490.

Carlson, J. A., Engelberg, J. K., Cain, K. L., Conway, T. L., Mignano, A. M., Bonilla, E. A., Geremia, C., \& Sallis, J. F. (2015). Implementing classroom physical activity breaks: Associations with student physical activity and classroom behavior. Preventive Medicine, 81, 67-72. https://doi.org/10.1016/j. ypmed.2015.08.006

Centers for Disease Control and Prevention. (2010). The association between school based physical activity, including physical education and academic performance. Atlanta, GA: U.S. Department of Health and Human Services, CDC.
Physical activity in special education classrooms 
Centers for Disease Control and Prevention. (2015). How much physical activity do children need? Retrieved from http://www.cdc.gov/physicalactivity/ basics/children/index.html

Chaddock-Heyman, L., Erickson, K. I., Voss, M., Knecht, A., Pontifex, M. B., Castelli, D., Hillman, C. H., \& Kramer, A. (2013). The effects of physical activity on functional MRI activation associated with cognitive control in children: A randomized controlled intervention. Frontiers in Human Neuroscience, 7,

Alicia Fedewa, Colleen Cornelius, Elizabeth Whitney, Soyeon Ahn, Mary Comis

Chang, Y. K., Labban, J. D., Gapin, J. I., \& Etnier, J. L. (2012). The effects of acute exercise on cognitive performance: A meta-analysis. Brain Research, 1453, 87101. https://doi.org/10.1016/j.brainres.2012.02.068
Davis, C. L., Tkacz, J. P., Tomporowski, P. D., \& Bustamante, E. E. (2015). Independent associations of organized physical activity and weight status with children's cognitive functioning: A matched-pairs design. Pediatric Exercise Science, 27, 477-487. https://doi.org/10.1123/pes.2015-0044

D’Haese, S., Cardon, G., De Bourdeaudhuij, I., Deforche, B., De Meester, F., \& Van Dyck, D. (2016). Changes in individual and social environmental characteristics in relation to changes in physical activity: A longitudinal study from primary to secondary school. International Journal of Behavioral Medicine, 23, 539-552. https://doi.org/10.1007/s12529-016-9545-z

Donnelly, J. E., Hillman, C. H., Castelli, D., Etnier, J. L., Lee, S., Tomporowski, P., Lambourne, K., \& SzaboReed, A. N. (2016). Physical activity, fitness, cognitive function, and academic achievement in children: a systematic review. Medicine and Science in Sports and Exercise, 48, 1197-1222. https://doi. org/10.1249/MSS.0000000000000901

Donnelly, J. E., \& Lambourne, K. (2011). Classroom-based physical activity, cognition, and academic achievement. Preventive Medicine, 52, 36-42. https://doi.org/10.1016/j.ypmed.2011.01.021

Elliot, C., Lang, C., Brand, S., Holsboer-Trachsler, E., Pühse, U., \& Gerber, M. (2015). The relationship between meeting vigorous physical activity recommendations and burnout symptoms among adolescents: An exploratory study with vocational students. Journal of Sport and Exercise Psychology, 37, 180-192. https://doi.org/10.1123/jsep.2014-0199

Fedewa, A. L., Abel, M., \& Erwin, H. E. (2017a). The effects of using stationary bicycle desks in classrooms on adolescents' physical activity. Journal of Occupational Therapy, Schools, \& Early Intervention, 10, 1-12. https://doi.org/10.1080/19411243.2016.1266457

Fedewa, A. L., \& Ahn, S. (2011). The effects of physical activity and physical fitness on children's achievement and cognitive outcomes: a meta-analysis. $R e$ search Quarterly for Exercise and Sport, 82, 521-535. https://doi.org/10.1080/02701367.2011.10599785

Fedewa, A. L., Cornelius, C., \& Ahn, S. (2017b). The use of bicycle workstations to increase physi- cal activity in a secondary school classroom. Health Psychology Report, 6, 60-74. https://doi. org/10.5114/hpr.2018.71211

Grieco, L. A., Jowers, E. M., \& Bartholomew, J. B. (2009). Physically active academic lessons and time on task: the moderating effect of body mass index. Medicine and Science in Sports and Exercise, 41, 1921-1926. https://doi.org/10.1249/MSS.0b013e3181a61495

Hardman, C. A., Horne, P. J., \& Lowe, C. F. (2011). Effects of rewards, peer-modeling and pedometer targets on children's physical activity: A schoolbased intervention study. Psychology \& Health, 26, 3-21. https://doi.org/10.1080/08870440903318119

Have, M., Nielsen, J. H., Gejl, A. K., Ernst, M. T., Fredens, K., Støckel, J. T., Wedderkopp, N., Domazet, S. L., Gudex, C., Grøntved, A., \& Kristensen, P. L. (2016). Rationale and design of a randomized controlled trial examining the effect of classroom-based physical activity on math achievement. BMC Public Health, 16, 1-11. https://doi.org/10.1186/s12889-0162971-7

Hernandez, B. L. (2014). Health, physical activity, and academic achievement: The role of teachers, schools, and communities. Journal of Physical Education, Recreation and Dance, 85, 8-10. https:// doi.org/10.1080/07303084.2014.876868

Hillman, C. H., Pontifex, M. B., Raine, L. B., Castelli, D. M., Hall, E. E., \& Kramer, A. F. (2009). The effect of acute treadmill walking on cognitive control and academic achievement in preadolescent children. Neuroscience, 159, 1044-1054. https://doi. org/10.1016/j.neuroscience.2009.01.057

Janssen, M., Chinapaw, M., Rauh, S., Toussaint, H., Mechelen, W. V., \& Verhagen, E. (2014a). A short physical activity break from cognitive tasks increases selective attention in primary school children aged 10-11. Mental Health and Physical Activity, 7, 129-134. https://doi.org/10.1016/j.mhpa.2014.07.001

Janssen, M., Toussaint, H. M., van Mechelen, W., \& Verhagen, E. A. (2014b). Effects of acute bouts of physical activity on children's attention: a systematic review of the literature. Springerplus, 3, 1-10.

Johnson, C. (2009). The benefits of physical activity for youth with developmental disabilities: A systematic review. American Journal of Health Promotion, 23, 157-167. https://doi.org/10.4278/ ajhp.070930103

Joubert, L. M., Kilgas, M. A., Holley, A. M., \& Drum, S. N. (2015). Feasibility of cycle desk use during a semester-long university lecture course: 1923 Board \#268 May 28, 3:30 PM-5:00 PM. Medicine \& Science in Sports \& Exercise, 47, 528-529.

Kibbe, D. L., Hackett, J., Hurley, M., McFarland, A., Schubert, K. G., Schultz, A., \& Harris, S. (2011). Ten Years of TAKE 10! ${ }^{\circledR}$ : Integrating physical activity with academic concepts in elementary school classrooms. Preventive Medicine, 52, S43S50. https://doi.org/10.1016/j.ypmed.2011.01.025 
King, M., Shields, N., Imms, C., Black, M., \& Ardern, C. (2013). Participation of children with intellectual disability compared with typically developing children. Research in Developmental Disabilities, 34, 1854-1862.

Kohl III, H. W., \& Cook, H. D. (eds.). (2013). Educating the student body: Taking physical activity and physical education to school. Washington, D.C.: National Academies Press.

Law, M., King, G., King, S., Kertoy, M., Hurley, P., Rosenbaum, P., Young, N., \& Hanna, S. (2006). Patterns of participation in recreational and leisure activities among children with complex physical disabilities. Developmental Medical Child Neurology, 48, 337342. https://doi.org/10.1017/S0012162206000740

Lounsbery, M. A., McKenzie, T. L., Trost, S., \& Smith, N. J. (2011). Facilitators and barriers to adopting evidence-based physical education in elementary schools (Supplemental). Journal of Physical Activity and Health, 8, 17-25. https://doi. org/10.1123/jpah.8.s1.s17

Luke, S., Vail, C. O., \& Ayres, K. M. (2014). Using antecedent physical activity to increase on-task behavior in young children. Exceptional Children, 80, 489503. https://doi.org/10.1177/0014402914527241

Mahar, M. T., Murphy, S. K., Rowe, D. A., Golden, J., Shields, A. T., \& Raedeke, T. D. (2006). Effects of a classroom-based program on physical activity and on-task behavior. Medicine and Science in Sports and Exercise, 38, 2086-2094. https://doi. org/10.1249/01.mss.0000235359.16685.a3

Martin, R., \& Murtagh, E. M. (2015). Preliminary findings of active classrooms: An intervention to increase physical activity levels of primary school children during class time. Teaching and Teacher Education, 52, 113-127. https://doi.org/10.1016/j. tate.2015.09.007

Mulrine, C. F., Prater, M. A., \& Jenkins, A. (2008). The active classroom: Supporting students with attention deficit hyperactivity disorder through exercise. Teaching Exceptional Children, 40, 16-22.

Mura, G., Vellante, M., Nardi, A. E., Machado, S., \& Carta, M.G.(2015). Effects of school-based physical activity interventions on cognition and academic achievement: a systematic review. CNS \& Neurological Disorders-Drug Targets 14, 1194-1208. https://doi.org/10.2174/1745017901511010077

Murphy, N. A., \& Carbone, P. S. (2008). Promoting the participation of children with disabilities in sports, recreation, and physical activities. American Academy of Pediatrics, 121, 1057-1061. https:// doi.org/10.1542/peds.2008-0566

National Center for Education Statistics. (2016). Back to school statistics. Retrieved from https://nces. ed.gov/fastfacts/display.asp?id=372

Ogden, C. L., Carroll, M. D., Kit, B. K., \& Flegal, K. M. (2014). Prevalence of childhood and adult obesity in the United States, 2011-2012. Journal of the American Medical Association, 311, 806-814. https://doi.org/10.1001/jama.2014.732

Owen, K. B., Parker, P. D., Van Zanden, B., MacMillan, F., Astell-Burt, T., \& Lonsdale, C. (2016). Physical activity and school engagement in youth: $A$ systematic review and meta-analysis. Educational Psychologist, 51, 129-145. https://doi.org/10.1080/0 0461520.2016 .1151793

Perkins, K., Columna, L., Lieberman, L., \& Bailey, J. (2013). Parents' perceptions of physical activity for their children with visual impairments. Journal of Visual Impairment and Blindness, 107, 131-142.

Pilcher, J. J., \& Baker, V. C. (2016). Task performance and meta-cognitive outcomes when using activity workstations and traditional desks. Frontiers in Psychology, 7, 957. https://doi.org/10.3389/ fpsyg.2016.00957

Pontifex, M., Hillman, C., Fernhall, B.O., Thompson, K., \& Valentini, T. (2009). The effect of acute aerobic and resistance exercise on working memory. Medicine Science in Sports Exercise, 41, 927-934. https://doi.org/10.1249/MSS.0b013e3181907d69

Pontifex, M. B., Scudder, M. R., Drollette, E. S., \& Hillman, C. H. (2012). Fit and vigilant: the relationship between poorer aerobic fitness and failures in sustained attention during preadolescence. Neuropsychology, 26, 407-413. https://doi.org/10.1037/ a0028795

Ralph, B. C., Onderwater, K., Thomson, D. R., \& Smilek, D. (2017). Disrupting monotony while increasing demand: benefits of rest and intervening tasks on vigilance. Psychological Research, 81, 432-444. https://doi.org/10.1007/s00426-016-0752-7

Ray, T. D., \& Henry, K. (2011). Self-efficacy and physical activity in children with congenital heart disease: Is there a relationship? Journal for Specialists in Pediatric Nursing, 16, 105-112. https://doi. org/10.1111/j.1744-6155.2011.00282.x

Rimmer, J. A., \& Rowland, J. L. (2008). Physical activity for youth with disabilities: A critical need in an underserved population. Developmental Neurorehabilitation, 11, 141-148. https://doi.org/10.1080/ 17518420701688649

Ross, S. E. T., Dowda, M., Beets, M. W., \& Pate, R. R. (2013). Physical activity behavior and related characteristics of highly active eighth-grade girls. Journal of Adolescent Health, 52, 745-751. https:// doi.org/10.1016/j.jadohealth.2012.12.003

Rutkowski, E. M., \& Connelly, C. D. (2012). Self-efficacy and physical activity inadolescent and parent dyads. Journal for Specialists in Pediatric Nursing, 17, 51-60. https://doi.org/10.1111/j.1744-6155.2011.00314.x

Schedlin, H., Lieberman, L. J., Houston-Wilson, C., \& Cruz, L. (2012). Academic learning time in physical education of children with visual impairments: An analysis of two students. Insight: Research and Practice in Visual Impairment and Blindness, 5, 11-22.
Physical activity in special education classrooms 
Schmidt, M., Benzing, V., \& Kamer, M. (2016). Classroom-based physical activity breaks and children's attention: Cognitive engagement works! Frontier in Psychology, 7, 1474. https://doi.org/10.3389/ fpsyg.2016.01474

Sit, C., McManus, A., McKenzie, T., \& Lian, J. (2007). Physical activity levels of children in special schools. Preventive Medicine, 45, 424-431. https:// doi.org/10.1016/j.ypmed.2007.02.003

Alicia Fedewa,

Sowa, M., \& Meulenbroek, R. (2012). Effects of physical exercise on autism spectrum disorders: A metaanalysis. Research in Autism Spectrum Disorders, 6, 46-57. https://doi.org/10.1016/j.rasd.2011.09

Colleen Cornelius, Elizabeth Whitney, Soyeon Ahn, Mary Comis

Staiano, A. E., Abraham, A. A., \& Calvert, S. L. (2012). Competitive versus cooperative exergame play for African American adolescents' executive function skills: short-term effects in a long-term training intervention. Developmental Psychology, 48, 337342. https://doi.org/10.1037/a0026938

U.S. Department of Health and Human Services. (2008). Physical activity guidelines advisory committee report. Washington, DC: U.S. Department of Health and Human Services.

Verburgh, L., Königs, M., Scherder, E. J., \& Oosterlaan, J. (2013). Physical exercise and executive functions in preadolescent children, adolescents and young adults: A meta-analysis. British Journal of Sports Medicine, 48, 973-979. https://doi. org/10.1136/bjsports-2012-091441

Webster, E. K., Wadsworth, D. D., \& Robinson, L. E. (2015). Preschoolers' time on-task and physical activity during a classroom activity break. Pediatric Exercise Science, 27, 160-167. https://doi. org/10.1123/pes.2014-0006

Whitt-Glover, M. C., Ham, S. A., \& Yancey, A. K. (2011). Instant Recess ${ }^{\circledR}$ : A practical tool for increasing physical activity during the school day. Progress in Community Health Partnerships: Research, Education, and Action, 5, 289-297.

World Health Organization. (2016). Report of the commission on ending childhood obesity. Geneva, Switzerland: WHO Document Production Services. Retrieved from http://apps.who.int/iris/bitstre am/10665/204176/1/9789241510066_eng.pdf

Zimmerman, B. J., Bandura, A., \& Martinez-Pons, M. (1992). Self-motivation for academic attainment: The role of self-efficacy beliefs and personal goal setting. American Educational Research Journal, 29, 663-676.

Zwier, J. N., van Schie, P. E., Becher, J. G., Smits, D. W., Gorter, J. W., \& Dallmeijer, A. J. (2010). Physical activity in young children with cerebral palsy. Disability and Rehabilitation, 2, 1501-1508. https:// doi.org/10.3109/09638288.2010.497017 